\title{
Teknik Vokal dan Pembawaan Lagu Keroncong Stambul "Tinggal Kengangan" Ciptaan Budiman BJ oleh Subarjo HS
}

\author{
Nadya Rany Sekar Pambajeng ${ }^{1}$, Suryati², dan Musmal ${ }^{3}$ \\ 1,2,3Program Studi Pendidikan Musik, Fakultas Seni Pertunjukan Institut Seni Indonesia
}

\begin{abstract}
This article is extracted from a study entitled "Vocal Technique And Stylized Keroncong Stambul Song"Tinggal Kenangan" Budiman BJ creation by Subardjo HS". There are a number of problems that are Reasons for doing more in-depth research and the results can be used as additional references. This sudy uses qualitative descriptive research methods as an approach in exploring the data and the stages that must be passed in accordance with the procedure. Data sources were obtained through observation, interviews, and documentation. In researching vocal technique and stylized keroncong stambul song Tinggal Kenangan Budiman BJ creation, especially first analyzing the keroncong vocal technique, the form and character of the stambul song, after analyzing the vocal technique and stylized keroncong stambul song Tinggal Kenangan Budiman BJ creation, then interviewing some actors keroncong music, including actors with background behind academics and practitioners of keroncong music. From the result of the study, it can be seen that the Vocal Technique And Stylized Keroncong Stambul Song Tinggal Kenangan Budiman BJ creation has the characteristic song and presented with technique and improvisation in accordance with styled by Subardjo HS.
\end{abstract}

Keywords: vocal technique, styled, keroncong stambul

\begin{abstract}
Abstrak
Artikel ini disarikan dari penelitian yang berjudul “Teknik Vokal Dan Pembawaan Lagu Keroncong Stambul “Tinggal Kenangan" Ciptaan Budiman BJ Oleh Subardjo HS". Ada beberapa permasalahan yang menjadi alasan untuk melakukan penelitian lebih mendalam dan hasilnya dapat digunakan sebagai referensi tambahan. Penelitian ini menggunakan metode penelitian deskriptif kualitatif sebagai pendekatan dalam menggali data-data serta tahapantahapan yang harus dilalui sesuai dengan prosedur. Sumber-sumber data diperoleh melalui metode observasi, wawancara, dan dokumentasi. Dalam meneliti teknik vokal dan pembawaan lagu keroncong stambul “Tinggal Kenangan” ciptaan Budiman BJ, terlebih dahulu menganalisa seputar teknik vokal keroncong, bentuk dan karakter lagu stambul. Setelah melakukan analisis pada teknik vokal dan pembawaan lagu keroncong stambul "Tinggal kenangan" ciptaan Budiman BJ, selanjutnya melakukan wawancara kepada beberapa pelaku musik keroncong, meliputi pelaku yang mempunyai latar belakang akademisi serta pelaku yang memang seorang praktisi musik keroncong. Dari hasil penelitian dapat diketahui bahwa teknik dan pembawaan lagu keroncong stambul "Tinggal Kenangan" ciptaan Budiman BJ mempunyai karakter dan ciri khas lagu yang mendayu, dan dibawakan dengan teknik dan improvisasi sesuai dengan pembawaan Subardjo HS.
\end{abstract}

Kata kunci: teknik vokal, pembawaan, keroncong stambul

\section{Pengantar}

Musik adalah suara yang disusun mengandung irama, lagu, dan keharmonisan terutama suara yang dihasilkan dari alat musik yang dapat menghasilkan irama.
Musik diartikan juga sebagai gambaran kehidupan manusia yang dinyatakan dalam bentuk bunyi yang berirama sebagai wujud pikiran dan perasaanya. Musik mengandung keindahan dan merupakan hasil cipta yang 
bersumber pada ketinggian budi dari jiwa. Musik selalu dijadikan tolak ukur dari tinggi rendahnya nilai-nilai dan karakter suatu bangsa. (Soeharto, 1996: 58)

Negara Indonesia merupakan negara yang sangat menjunjung tinggi nilai-nilai dan karakter warisan dari nenek moyang salah satunya musik keroncong, di mana musik keronong adalah salah satu kebudayaan khas Bangsa Indonesia yang sampai saat ini masih dilestarikan. Sejarah mengenai munculnya musik keroncong di Indonesia merupakan proses yang sangat panjang. Terdapat beberapa pendapat mengenai keberadaan musik keroncong, di antaranya ada yang mengatakan bahwa sejarah musik keroncong dimulai pada abad ke-17 ketika kaum mardjikers keturunan Portugis mulai memperkenalkanya di Batavia.

Tulisan-tulisan A.Th. Manusama dkk menyatakan musik keroncong bukanlah kesenian asli ciptaan Bangsa Indonesia, namun Kusbini seorang ahli musik keroncong yang terpandang di Indonesia berpendapat bahwa musik keroncong adalah asli ciptaan bangsa Indonesia, pendapat ini disampaikan dalam suatu ceramahnya pada acara yang diselenggarakan oleh Tim Olah Seni Indonesia (TOSI) pada tanggal 28 Desember 1970 di Yogyakarta, Kusbini menambahkan bahwa lagu-lagu keroncong Indonesia memang banyak dipengaruhi dan diilhami oleh bangsa-bangsa Portugis pada abad ke-16, tetapi nada iramanya sangat berbeda. Meskipun ada perbedaan tersebut, patutlah disadari keberadaan musik keroncong di Indonesia dimulai pada abad ke-17 pada saat bangsa Portugis datang ke Batavia (Munjid, 2001: 10), adapun yang berpendapat bahwa nama "Keroncong" ini berasal dari bunyi gelang kaki penari Ngremo (tarian dari Madura). Penari ini berpakaian seperti pelaut Madura dengan ditambah sepasang gelang kelinthing di mata kakinya (Becker, 1975: 15).
Musik keroncong tidak banyak diminati terutama dikalangan anak muda, karena musik keroncong identik dengan musik yang kuno atau ketinggalan jaman. Sebagian kalangan anak muda kurang berminat belajar musik keroncong karena musik keroncong sulit untuk dimainkan atau dibawakan. Salah satu kesulitan musik keroncong adalah cara pembawaannya, adapun dalam pembawaan lagu keroncong terdapat beberapa teknik antara lain seperti cengkok, gregel, embat dan nggandul (penjelasan ada pada bab 4). Musik keroncong terbagi menjadi beberapa jenis, yaitu: keroncong asli, langgam, stambul dan lagu ekstra (bukan bentuk keroncong,tapi lagunya dimainkan dengan irama keroncong). Pada beberapa jenis keroncong tersebut, masyarakat sudah tidak asing mendengar dan menyanyikan beberapa lagu keroncong jenis keroncong asli, langgam dan lagu ekstra, sedangkan musik keroncong jenis stambul kurang dikenal oleh masyarakat luas. Hal ini menjadi menarik bagi penulis karena memiliki keunikan tersendiri seperti pola harmoni dan bentuk lagu.

Stambul merupakan jenis keroncong yang namanya diambil dari bentuk sandiwara yang dikenal pada akhir abad ke19 hingga paruh awal abad ke-20. Di Indonesia stambul lebih dikenal dengan nama Komedi stambul. Nama "stambul" diambil dari Istambul di Turki. Salah satu kekhasan yang dimiliki musik stambul adalah permainan gitar yang dimainkan secara instrumental tunggal (melodi gitar dibawakan secara recitative). Stambul dinikmati di suasana malam yang sepi dan tenang. Nuansa musik stambul hampir sama dengan musik padang pasir dari timur tengah. Hal ini dikarenakan musik stambul dibawa ke Indonesia pada saat Perang Dunia 1 oleh para musisi Indonesia yang telah berkerja di Turki sebagai ungkapan simpati terhadap negeri Timur Tengah. Banyak juga yang menganggap bahwa stambul dan 
keroncong adalah jenis musik yang sama (Harmunah, 2011:18).

Berdasarkan pengalaman, penulis sering menemui kesulitan dalam memahami bagaimana pembawaan saat bernyanyi keroncong terutama jenis keroncong stambul, dimana terdapat beberapa teknik dan pembawaan tersendiri dalam membawakannya. Melihat permasalahan tersebut, penulis ingin mengkaji tentang pembawaan lagu keroncong stambul “Tinggal Kenangan" Ciptaan Budiman BJ menggunakan teknik vokal dan pembawaan oleh Subardjo HS. Maka dari itu, hal ini menjadi alasan penulis untuk menyusun karya tulis.

Lagu keroncong stambul "Tinggal Kenangan" merupakan kategori lagu stambul II, di mana lagu ini memiliki 2 kali 16 birama atau 32 birama dan diawali dengan recitative oleh vokal. Lagu keroncong stambul "Tinggal Kenangan" di tulis oleh Budiman BJ. Budiman BJ adalah pimpinan dari Orkes Keroncong Bintang Jakarata. Nama belakang Budiman yaitu BJ adalah singkatan dari Bintang Jakarta, diambil dari nama Orkes Keroncong yang dipimpinnya. Nama BJ sudah melekat dengan Budiman dan menjadi nama kebesaran Budiman yang lebih dikenal dengan nama Budiman BJ hingga sekarang.

Subardjo HS adalah sosok penyanyi yang sudah melegenda. Nama HS adalah nama orangtuanya yang bernama Hardjo Sumarto dan nama tersebut sudah melekat dengan Subardjo dan menjadi nama kebesaran Subardjo yang lebih dikenal dengan nama Subardjo HS. Pengalamannnya bernyanyi keroncong dari tahun 1964 dan menjuarai berbagai lomba keroncong membuat Subardjo HS memilliki banyak ilmu dalam bagaimana cara menyanyikan lagu keroncong yang baik, benar dan enak didengar, salah satunya lagu stambul, sehingga Subardjo HS sangat paham tentang bagaimana teknik dan cara pembawaan lagu keroncong stambul salah satunya lagu keroncong stambul "Tinggal Kenangan" ciptaan Budiman BJ.

Berdasarkan uraian di atas, peneliti akan merumuskan masalah dalam penelitian ini sebagai berikut: (1) Bagaimana teknik vokal keroncong oleh Subardjo. HS dalam lagu stambul "Tinggal Kenangan" Ciptaan Budiman. BJ? (2) Bagaimana pembawaan Subardjo. HS dalam lagu keroncong stambul “Tinggal Kenangan” Ciptaan Budiman. BJ?

Tujuan dari penelitian ini adalah (1) Untuk mengetahui bagaimana teknik vokal keroncong oleh Subardjo. HS dalam lagu stambul "Tinggal Kenangan" Ciptaan Budiman. BJ, (2) Untuk mengetahui bagaimana pembawaan Subardjo. HS dalam lagu keroncong stambul "Tinggal Kenangan" Ciptaan Budiman. BJ.

Manfaat dari penelitian ini adalah supaya mengetahui bagaimana teknik dan pembawaan keroncong khususnya lagu stambul "Tinggal Kenangan" ciptaan Budiman BJ oleh Subardjo HS. Hasil penelitian ini juga dapat menjadi rujukan bagi masyarakat khususnya kaum muda yang ingin belajar vokal keroncong.

Metode yang digunakan dalam penyusunan karya tulis ini adalah metode penelitian jenis kualitatif dengan pendekatan deskriptif analisis, karena data yang diungkapkan tidak memaparkan bilangan atau jumlah tetapi berupa uraian dan informasi-informasi mengenai suatu keadaan. Menurut Sugiyono (2013:15) metode kualitatif adalah metode yang menggunakan obyek yang bersifat alamiah (obyek apa adanya). Penelitian kualitatif sebagai human instrumen, berfungsi menetapkan fokus penelitian, memilih informan sebagai sumber data, melakukan pengumpulan data, analisis data dan membuat kesimpulan atas temuanya (Sugiyono, 2012: 222). Instrumen dalam penelitian ini adalah daftar wawancara, dimana peneliti sendirilah yang melakukan 
pengumpulan data tertulis maupun terekam dari para narasumber maupun informan dengan wawancara.

Pengumpulan data adalah tahap pencarian data atau informasi yang berhubungan langsung dengan bahan yang dibutuhkan oleh penulis. Teknik pengumpulan data merupakan langkah yang paling utama dalam penelitian, karena tujuan utama dari penelitian adalah mendapatkan data (Sugiyono, 2012: 224). Adapun sumber data yang diperoleh yaitu: a. Studi kepustakaan, b. Observasi, c. Wawancara, d. Dokumentasi.

Teknik analisis data merupakan proses mencari dan menyusun secara sistematis data yang diperoleh dari hasil wawancara, catatan lapangan dan dokumentasi dengan cara mengorganisasikan data kedalam kategori,menjabarkan kedalam unit-unit, melakukan sintesa, menyusun kedalam pola,memilih mana yang penting dan yang akan dipelajari kemudian membuat kesimpulan (Sugiyono, 2012: 244).

Sebuah penelitian sudah tentu memerlukan referensi sebagai rujukan literatur yang relevan dengan topik penelitian. Beberapa pustaka yang digunakan antara lain: BJ, Budiman. (1979). Mengenal Keroncong Dari Dekat. Buku ini menguraikan tentang pengetahuan musik keroncong dari yang paling dasar, dan uraian alat-alat musik keroncong pada umumnya yang akan membantu dalam membahas musik keroncong ditinjau dari segi apa itu musik keroncong, lagu-lagu keroncong, irama keroncong, dan instrumen keroncong. Buku ini juga membantu dalam menganalisa teknik dan pembawaan lagu keroncong stambul "Tinggal Kenangan" ciptaan Budiman BJ.

Ganap, V. (2011). Kerontjong Toegoe. Buku ini berisi tentang awal mula lahirnya Keroncong Tugu, di mana merupakan awal mula lahirnya musik keroncong di Indonesia sehingga membantu penulisan dalam hal sejarah dan perkembangan musik keroncong di Indonesia. Harmunah. (1987). Sejarah. Gaya dan Perkembangan Musik Keroncong. Buku ini menguraikan tentang latar belakang sejarah musik keroncong. Selanjutnya memaparkan tentang perkembangan musik keroncong yang membantu penulisan khususnya dalam pengetahuan sejarah musik keroncong dan gaya bermain musik keroncong.

Kusbini. (1976). Sejarah Kehidupan Perkembangan dan Asal Usul Musik Kerontjong Indonesia. Buku ini berisi tentang asal usul dan sejarah perkembangan musik keroncong di Indonesia dari dulu hingga sekarang. Buku ini juga membantu penulis melengkapi data. Lisbijanto, H. (2013). Musik Keroncong. Buku ini membahas tentang sejarah masuknya dan penyebaran musik keroncong di Indonesia sehingga dapat dikenal oleh masyarakat luas. Buku ini juga memaparkan tentang alat musik keroncong yang membantu penulis melengkapi data. Pramayuda. (2010). Teknik Bernyanyi. Buku ini berisi tentang apa saja yang harus diperhatikan saat bernyanyi dan bagaimana bernyanyi menggunakan teknik dengan baik dan benar. Buku ini membantu penulis melengkapi data tentang teknik bernyanyi secara umum.

Pranadjaja. (1976). Seni Menyanyi. Buku ini membahas tentang teknik dasar vokal yang dipakai saat bernyanyi, sikap tubuh yang benar saat bernyanyi dan bagaimana cara penerapannya pada saat berlatih. Soeharto. (1996). Serba-Serbi Keroncong. Buku ini membahas tentang sejarah keroncong, asal mula keroncong. Buku ini juga memaparkan tentang evolusi dan macam-macam alat musik keroncong, bentuk dan pola harmoni semua jenis keroncong yang membantu penulis melengkapi data.

Widjajadi, R. A. (2007). Mendayung di Antara Tradisi dan Modernitas (Sebuah Penjelajahan Ekspresi Budaya Terhadap Musik 
Keroncong). Buku ini menjabarkan suatu pengamatan dari perspektif musikologis serta sosio-budayanya. Menyimak dan memandang lebih luas, musik keroncong adalah perpaduan dua budaya musikal yang berbeda, yaitu budaya barat (moderen) dan budaya lokal (tradisional). Wiranto. (1994). Diktat Ilmu

Karawitan. Buku ini membahas tentang teknik-teknik bernyanyi karawitan dan beberapa teknik pada karawitan berkaitan dengan teknik bernyanyi keroncong. Buku ini juga memaparkan beberapa persamaan teknik bernyanyi karawitan dan keroncong. Sugiyono. (2012). Metode Kuantitatif, Kualitatif dan R\&D. Buku ini membahas tentang macam-macam metode dan menjabarkan secara rinci macam-macam metode yang digunakan dalam penelitian. Buku ini membantu penulis melengkapi data.

\section{Pembahasan}

A. Teknik vokal lagu keroncong stambul "Tinggal Kenangan" ciptaan Budiman BJ yang dibawakan oleh Subardjo HS.

\section{Pernapasan}

Subardjo HS, menyanyikan lagu stambul "Tinggal kenangan" menggunakan pernapasan diafragma akan lebih halus saat menyanyikan kalimat pertama dan nafas yang dikeluarkan jauh lebih kuat daripada menggunakan pernapasan dada. Frase pada lagu stambul "Tinggal kenangan" ini sangat panjang dan membutuhkan napas yang kuat. 2. Resonansi

Pada saat membawakan lagu stambul “Tinggal kenangan",Subardjo menggunakan resonansi atas atau resonansi kepala dan resonansi dada. Menurut

Subardjo penggunaan resonansi atas atau resonansi kepala sangat berpengaruh pada lagu stambul "Tinggal kenangan" terutama pada nada-nada tinggi. Begitu juga dengan penggunaan resonansi dada. Resonansi dada juga sangat penting pada lagu stambul Tinggal kenangan" untuk menjangkau nada-nada bawah. Contoh frase yang menggunakan resonansi kepala :

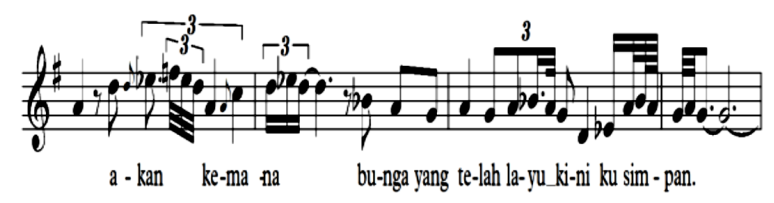

Notasi 1. Nada atas yang dinyanyikan dengan resonansi kepala

Contoh frase yang menggunakan resonansi dada:

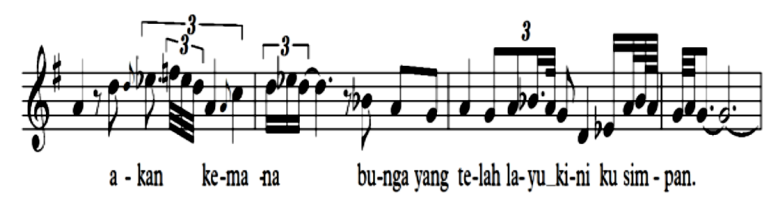

Notasi 2. Nada atas yang dinyanyikan dengan resonansi dada

\section{Karakter suara (Warna suara)}

Pada lagu stambul "Tinggal Kenangan" ini Subardjo berkata bahwa lagu stambul adalah lagu yang dibawakan dengan mendayu-dayu. Jadi warna suara juga harus mendukung dalam membawakan lagu tersebut. Disini Subardjo menggunakan warna suara ringan dan terang, namun tetap beresonansi. Arti ringan dan terang namun tetap beresonansi disini yaitu tidak ditekan atau tidak terlalu didorong, tetapi tetap lembut. Menurut Subardjo jika terlalu ditekan atau terlalu didorong warna suara yang dihasilkan bukan ringan dan terang, tetapi terkesan "berteriak".

4. Artikulasi

Artikulasi adalah pengucapan atau pelafalan kata-kata dengan jelas, baik, dan benar. Pada lagu stambul "Tinggal Kenangan" ini Subardjo berkata bahwa setiap kata-kata atau syair pada lagu ini harus dinyanyikan dengan jelas, seperti huruf konsonan A, I, U, E dan O. Menurut Subardjo, saat bernyanyi bentuk mulut harus terbuka dengan sedikit terbuka kesamping, tidak terlalu bulat dan tidak terlalu kesamping. Pada nada rendah dan nada 
tinggi bentuk mulut saat bernyanyi harus sama, agar syair pada lagu stambul "Tinggal Kenangan" terdengar dengan jelas.

B. Pembawaan Lagu Keroncong Stambul "Tinggal Kenangan" Ciptaan Budiman BJ Oleh Subardjo HS.

\section{Ekspresi}

Ekspresi adalah pengungkapan maksud,perasaan, atau gagasan dalam bentuk nyata. Pada saat bernyanyi, penyanyi menyampaikan isi lagu dengan berekspresi dalam bentuk mimik muka. Dalam berekspresi penyanyi satu dengan lainnya akan beda cara menyampaikannya, tergantung dengan isi lagunya.

Pada lagu keroncong stambul "Tinggal Kenangan" ciptaan Budiman BJ, Subardjo HS berkata bahwa saat mengekspresikan lagu tersebut harus tahu terlebih dahulu arti dan maksut dari setiap lirik dalam lagu tersebut agar sesuai saat menyampaikan isi lagu keroncong stambul "Tinggal Kenangan" ciptaan Budiman BJ. Ekspresi juga sangat penting saat bernyanyi, karena tanpa ekspresi lagu yang dibawakan tidak akan hidup dan terkesan datar.

2. Improvisasi

Improvisasi adalah suatu ciptaan yang bersifat spontan dan terjadi seketika itu juga. Dalam bernyanyi keroncong, improvisasi mencakup berbagai teknikteknik bernyanyi keroncong seperti berikut: a. Cengkok

Cengkok merupakan hiasan pada nada pokok yang bergerak naik kemudian bergerak turun dan kembali lagi ke nada pokok. Cengkok dalam musik klasik disebut juga dengan gruppetto ( ). Cara menyanyikan cengkok keroncong berbeda dengan teknik khas gaya keroncong yang lain, umumnya cengkok dinyanyikan dengan cepat namun tetap luwes.
Notasi asli :

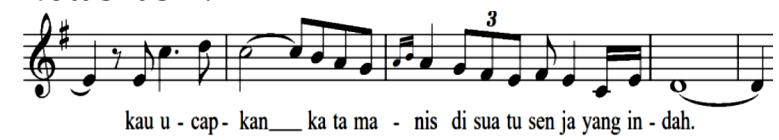

Notasi 3. Penggalan notasi stambul “Tinggal Kenangan"

Dengan Cengkok :

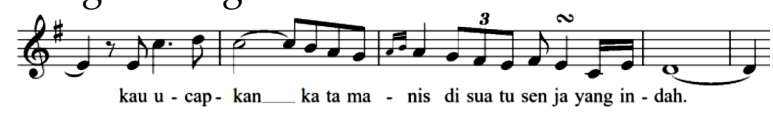

Notasi 4. Bentuk cengkok

Dinyanyikan :

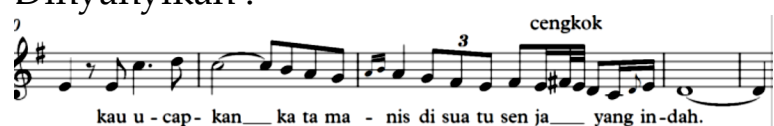

Notasi 5. Cara menyanyikan cengkok

Pada lagu keroncong stambul “Tinggal Kenangan” ciptaan Budiman BJ, Subardjo memberi sentuhan cengkok hampir di semua frase. Dalam satu lagu hanya terdapat satu atau dua sentuhan cengkok pada frase yang berbeda.

Menurut subardjo teknik cengkok (menyengkok) pada lagu keroncong stambul “Tinggal Kenangan" ciptaan Budiman BJ harus berhati-hati karena jika tidak, maka nada yang di cengkok cenderung tidak enak di dengar atau dalam istilah musiknya yaitu fals. Pada saat membawakan lagu keroncong stambul "Tinggal Kenangan" ciptaan Budiman BJ, cengkok juga jangan terlalu ramai (sewajarnya aja) agar lagu terkesan lebih indah.

b. Gregel

Gregel merupakan cengkok hiasan yang bergerak cepat. Gregel dinyanyikan dengan cara memantulkan nada diatas nada asli dengan cepat namun tetap luwes. Gregel dalam musik klasik disebut juga dengan mordent ( ). Gregel sering berada di akhir frase tapi juga ada yang terdapat di tengah frase dan tidak semua frase mendapatkan sentuhan gregel. Beberapa frase yang mendapat sentuhan gregel umumnya terdapat di ketukan akhir pada setiap birama. 
Notasi asli :

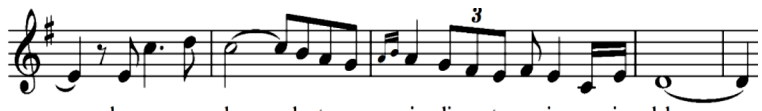

kau u - cap - kan__ ka ta ma - nis di sua tu sen ja yang in - dah.

Notasi 14. Penggalan notasi stambul "Tinggal Kenangan"

Dengan gregel :

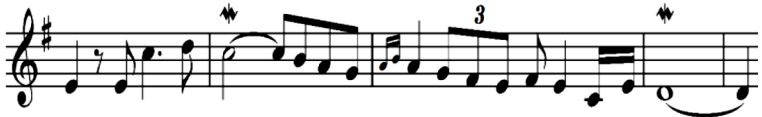

kau u - cap- kan_ ka ta ma - nis di sua tu sen ja yang in-dah.

Notasi 15. Bentuk gregel

Dinyanyikan :

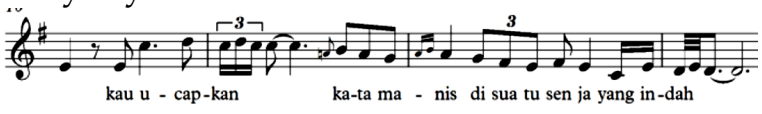

Notasi 16. Cara menyanyikan gregel

c. Embat

Embat dibagi menjadi 2, yaitu embat naik dan embat turun. Embat naik adalah teknik vokal keroncong dimana dinyanyikan dengan menambahkan nada terdekat sebelum nada pokok dalam suatu melodi yang dimainkan secara cepat dan tepat pada ketukan. Embat turun adalah teknik vokal keroncong dimana dinyanyikan dengan menambahkan nada terdekat sesudah nada pokok dalam suatu melodi yang dimainkan secara cepat dan tepat pada ketukan. Teknik embat dalam istilah musik klasik barat disebut dengan appoggiatura ( ).

Notasi asli I:



Notasi 23. Penggalan notasi stambul “Tinggal Kenangan"

Dengan embat naik:

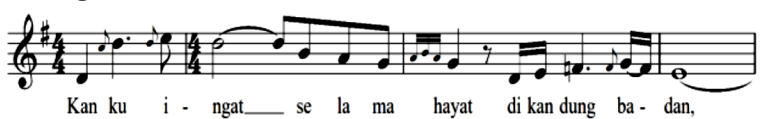

Notasi 24. Bentuk embat naik

Notasi asli II:

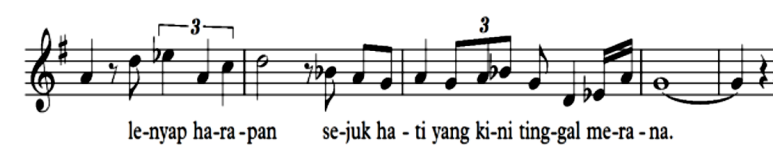

Notasi 25. Penggalan notasi stambul “Tinggal Kenangan"

Dengan embat turun

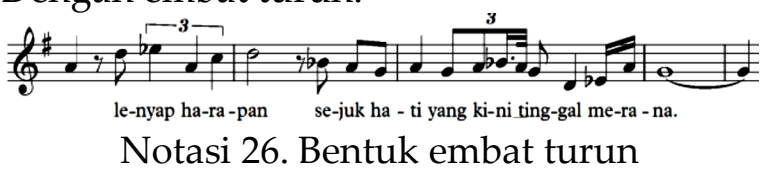

Berdasarkan wawancara dengan Soebarjo HS pada tanggal 19 Oktober 2018, beliau berpendapat bahwa teknik ngembat harus disesuaikan dengan kemampuan untuk menghimpun nafas agar embat itu sendiri terdengar utuh atau tidak terlihat seperti kehabisan nafas. Dengan kata lain embat harus dinyanyikan seenak dan senyaman mungkin. Apabila dalam memberi sentuhan embat tersebut tidak maksimal, maka hal ini biasanya diistilahkan kurang "Ngroncongi" atau nuansa keroncongnya kurang terlihat.

d. Nggandul

Nggandul, yaitu cara bernyanyi dengan ritme sebagai patokan mundur $1 / 2$ ketuk dari hitungan ritme Bas, namun jatuhnya ketukan akan pas pada frase akhir. Pada orkestra besar teknik nggandul cenderung dilakukan tidak terlalu sering atau terlalu banyak karena akan menghilangkan rasa dan makna dari lagu serta tempo menyanyi akan tertinggal dengan tempo iringan (kenggandulen).

Teknik nggandul atau istilah lain yaitu menggantung maat, merupakan teknik yang sangat fleksibel. Maksud dari fleksibel itu sendiri yaitu bernyanyi dengan agak sedikit mundur dari ketukan aslinya dalam satu frase, namun pada bagian tertentu pada frase yang sama, penyanyi harus mengejar ritme yang tertinggal akibat mundur dari ketukan yang seharusnya (mulur-mungkret).

Menurut Subardjo nggandul adalah ciri khas dari bernyanyi keroncong. Perlu dipahami juga bahwa tidak semuanya dalam 
satu lagu dibawakan dengan nggandul, karna resikonya akan ketinggalan tempo atau maat jika terlalu nggandul. Subardjo mengatakan bahwa setelah nggandul lebih bagusnya jika dioyak atau dimungkret, agar tidak ketinggalan tempo saat bernyanyi. Pembawaan improvisasi setiap orang saat bernyanyi keroncong pasti berbeda-beda dan akan berbeda juga pembawaan pada keesokan harinya. Subardjo berkata, saat membawakan lagu keroncong stambul “Tinggal Kenangan" ciptaan Budiman BJ, cengkok, gregel, embat, dan nggandul yang dibawakan pada saat ini akan berbeda dengan pembawaan keesokan harinya. Pembawaan yang berbeda-beda bisa dipengaruhi dari suasana ataupun musik yang mengiringi saat bernyanyi, jadi pembawaan pada saat ini dan besok tidak selalu sama.

\section{Dinamika}

Dinamika adalah keras dan lembutnya suara yang dikeluarkan oleh penyanyi. Dinamika juga perlu diperhatikan saat bernyanyi, seperti bernyanyi keroncong. Pada saat bernyanyi tidak semua dibawakan dengan keras ataupun dibawakan dengan lembut, oleh karna itu pada lagu keroncong stambul "Tinggal Kenangan" ciptaan Budiman BJ, Subardjo akan membawakan dengan dinamika.

4. Struktur kalimat (Frasering)

Struktur kalimat atau frasering adalah pemenggalan kalimat yang baik dan benar sehingga kalimat lagu tersebut dapat memberikan, menjelaskan tema dan menyampaikan pesan dari lagu atau karya yang dibawakan kepada pendengar pada saat bernyanyi. Dalam lagu keroncong stambul "Tinggal Kenangan" ciptaan Budiman BJ, Subardjo HS akan menyanyikan frase demi frase beserta pemenggalan kalimatnya.

\section{Penutup}

Berdasarkan pembahasan tentang Teknik Vokal Dan Pembawaan Lagu
Keroncong Stambul "Tinggal Kenangan" Ciptaan Budiman Bj Oleh Subarjo. Hs, teknik vokal keroncong merupakan hal yang sangat penting dipelajari dan diketahui oleh setiap penyanyi keroncong karena disinilah letak kesulitan menyanyikan lagu keroncong stambul.

Kesulitan membawakan lagu keroncong stambul yaitu bernyanyi dengan lembut dan halus namun tetap beresonan, jika resonansi yang digunakan tidak dikontrol atau terlalu didorong maka suara yang dihasilkan akan "kasar" dan karakter keroncong stambul pada lagu "Tinggal Kenangan" ciptaan Budiman BJ tidak tersampaikan. Setiap penyanyi memiliki karakter dan teknik vokal yang mempunyai ciri khas sendiri dalam membawakan lagu, seperti Subardjo HS dalam membawakan lagu keroncong stambul "Tinggal Kenangan" Ciptaan Budiman BJ.

Pembawaan keroncong stambul “Tinggal Kenangan” Ciptaan Budiman Bj secara umum hampir sama dengan pembawaan keroncong pada umumnya, seperti cengkok, gregel, embat dan nggandul, hanya saja ada beberapa perbedaan dalam cara pembawaanya. Pada pembawaan keroncong stambul "Tinggal Kenangan".

\section{Referensi}

Becker, J. (1975). Keroncong Indonesia Popular Music. Southeast Asia: Asian Music, Volum VII, No. I.

BJ, B. (1979). Mengenal Keroncong Dari Dekat. Jakarta: Perpustakaan Akademi Musik Lembaga Pendidikan Kesenian Jakarta.

Ganap, V. (2011). Kerontjong Toegoe. Yogyakarta: Badan Penerbit Institut Seni Indonesia.

Harmunah. (1987). Sejarah. Gaya dan Perkembangan Musik Keroncong. Yogyakarta: Pusat Musik Liturgi Yogyakarta. 
Kusbini. (1976). Sejarah Kehidupan Perkembangan dan Asal Usul Musik Kerontjong Indonesia. Yogyakarta: Sanggar Olah Seni Indonesia.

Lisbijanto, H. (2013). Musik Keroncong. Yogyakarta: Graha Ilmu.

Nasution. (1988). Langkah-langkah Penelitian. Jakarta. Pramayuda. (2010). Teknik Bernyanyi. Yogyakarta: Kanisius.

Pranadjaja. (1976). Seni Menyanyi. Jakarta: C.V Baru.

Sanjaya, S. (1985). Mengenal Instrumen Flute. Yogyakarta: Sekolah Menengah Musik.

Soeharto, A. S. (1996). Serba-Serbi Keroncong. Jakarta: Musika.

Sugiyono. (2012). Metode Kuantitatif, Kualitatif dan R\&D. Bandung:alfabeta.

Suryati. (2017). Teknik vokalisasi Seni Baca Al-Quran Dalam Musabaqoh Tilawatil Qur'an. Yogyakarta: Jurusan Musik Fakultas Seni Pertunjukan Institut Seni Indonesia Yogyakarta.

Widjajadi, R. A. (2007). Mendayung di Antara Tradisi dan Modernitas (Sebuah Penjelajahan Ekspresi Budaya Terhadap Musik Keroncong). Yogyakarta: Hanggar Kreator.

Wiranto. (1994). Diktat Ilmu Karawitan. Surakarta: Konservatori Karawaitan. Nurbeni, Ismunandar, Diecky Kurniawan Indrapraja. 2014. Peningkatan Keterampilan Menggunakan Gitar Akustik dengan Metode Tutor Sebaya di SMP. Jurnal: Program Studi Pendidikan Seni Tari dan Musik FKIP UNTAN, Pontianak

Setyo Kurniawan Saputro. 2013. Peningkatan Kompetensi Bermain Gitar dengan Media Gambar pada Siswa Kelas VIII-A SMP Negeri 2 Banjarharjo Kabupaten Brebes Tahun Ajaran
2011/2012. Skripsi: Jurusan Pendidikan Seni Drama Tari dan Musik Fakultas Bahasa dan Seni Universitas Negeri Semarang

Siswoyo, Dwi. 2007. Ilmu Pendidikan. Yogyakarta: UNY Press

Suyono dan Hariyono. 2015. Belajar dan Pembelajaran: Teori dan Konsep Dasar. Bandung: PT. Remaja Rosdakarya.

Syaiful Bahri Djamarah dan Aswan Zain. 2006. Strategi Belajar Mengajar. Jakarta: PT. Rineka Cipta

Wijaya Kusumah dan Dedi D Dwitagama. 2012. Mengenal Penelitian Tindakan Kelas Edisi Dua. Jakarta: PT. Indeks. 